\title{
Comparative Characteristics of The 1st Biochemical Screening Results in Pregnant Females With Thrombophilic Polymorphisms
}

\author{
E.S. Korosteleva, O.Iu. Ivanova* \\ Kursk State Medical University, 3, Karla Marksa Street, Kursk, 305041, Russia \\ *Corresponding Author: O.Iu. Ivanova, Kursk State Medical University, 3, Karla Marksa Street, Kursk, \\ 305041, Russia; Tel: +7 905041 82 89; E-mail: ivanovao1@mail.ru
}

Received: 19 March 2018; Accepted: 26 March 2018; Published: 28 March 2018

Thrombophilic polymorphisms are ethiopathological triggers of reproductive losses and pregnancy complications [1]. Implantation, trophoblast invasion and further placental functioning are objectively impaired in the presence of genetic coagulation defects [2,3].

The purpose of our research was to study the trophoblast function in early pregnancy in females of the Kursk region with genetic trombophilic polymorphisms.

115 female patients were included into the retrospective study. The main group consisted of 78 patients with reproductive losses after 12 gestation weeks against the background of genetic trombophilic polymorphisms. The control group was comprised of 37 patients with uncomplicated pregnancy and delivery, without trombophilic polymorphisms, who gave birth to healthy full-term infants.

The following parameters were analyzed: clinical history of patients, levels of $\beta$-subunit of human chorionic gonadotrophin ( $\beta$-hCG) and pregnancy-associated plasma protein A (PAPP-A) during the $1^{\text {st }}$ screening.

The mean patient age in the main group was $31.5 \pm 3.7$ years. The females in the main and control groups were comparable by age ( $>0.05)$. Among extragenital diseases, cardiovascular diseases $(94.8 \%$ (74)) were predominant in the main group; varicose vein disease of lower extremities was detected in 52.6\% (41) patients, lipid metabolism disorders in $48.7 \%$ (38) cases, as well as inflammatory diseases of the urinary tract (in remission during pregnancy) were diagnosed $(48.7 \%$ (38)). The number of females with extragenital diseases in the control group was significantly lower compared to the main one $(\mathrm{p}<0.01)$. 
Obstetric history analysis revealed that the overwhelming majority of the main group females were multigravida (65.4\% - 51), 15.4\% (12) patients were multipara. The control group mainly consisted of primigravida and primipara females $(75.7 \%-28)$.

$10.3 \%$ (8) females were diagnosed with an isolated MTHFR: 677C/T defect. Polygenic mutations were detected in $89.7 \%$ (70) patients. The combination of two mutations was found in $48.6 \%$ (34) pregnant women, three mutations in $27.1 \%$ (19), four mutations in $18.6 \%$ (13), and five mutations in $5.7 \%$ (4). The most common combination of genetic trombophilic polymorphisms in case of two mutations was MTHFR: 677C/T and PAI-1: 675 5G/4G. For three mutations it was the genetic polymorphism MTHFR: 677C/T, MTRR:A66G, and MTR:A2756G; for four mutations, that was MTHFR:677C/T, MTRR:A66G, MTR:A2756G, and PAI-1: 675 5G/4G.

The analysis of biochemical screening results in the main group revealed that the 1-1.5 MoM range (1.306 \pm 189 $\mathrm{MoM})$ for $\beta$-hCG included data for $43.6 \%$ (34) patients; in 56.4\% (44) females, $\beta$-hCG level was $<1(0.653 \pm 167$ MoM). PAPP-A parameters showed that the 1-1,5 MoM range comprised the parameters for $37.2 \%$ (29) patients $(1.418 \pm 87 \mathrm{MoM})$, in $42.3 \%$ (33) patients PAPP-A level was < 1 (0.762 $\pm 204 \mathrm{MoM})$, while in $20.5 \%$ (16) it was > 1.5 MoM (1.589 $\pm 84 \mathrm{MoM})$. For control group females, $\beta$-hCG and PAPP-A parameters were within 1-1.5 MoM $(1.322 \pm 105 \mathrm{MoM})$.

It was demonstrated that the overwhelming majority of pregnant women with thrombophilic polymorphisms had a decreased hormonal trophoblast function, which was reflected by $\beta$-hCG and PAPP-A parameters during the $1^{\text {st }}$ biochemical screening $(\mathrm{p}<0.05)$.

\section{References}

1. M.V. Khruslov, O.Iu. Ivanova, M.I. Boeva, E.S. Kosinova. Detection of conditions with possible positive pregnancy outcomes in females with hereditary thrombophilias. Thrombosis, hemostasis, and reology 67S3 (2016) 441-442.

2. E.V. Alegina, N.K. Tetruashvili, A.A. Agadzhanova et al. Genetic polymorphism as a factor predisposing to habitual pregnancy losses. Obstetrics and gynecology 4 (2014): 25-31.

3. A.D. Makatsaria, F.A. Chervenak, V.O. Bitsadze. High-risk pregnancy. Medical Information Agency JSC 2015: 920 .

Citation: E.S. Korosteleva, O.Iu. Ivanova. Comparative Characteristics of The 1st Biochemical Screening Results in Pregnant Females With Thrombophilic Polymorphisms. Obstetrics and Gynecology Research 1 (2018): 019-020.

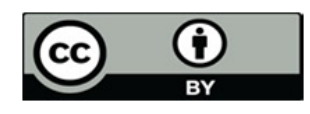

This article is an open access article distributed under the terms and conditions of the Creative Commons Attribution (CC-BY) license 4.0 